\title{
Effects of Perceived Smoking-Cancer Relationship and Cardiovascular Health Attitudes on Childrens' Views of Smoking
}

\author{
Ilknur Bektas*, Murat Bektas, Yasemin Selekoğlu, Aslı Akdeniz Kudubes, Sema \\ Sal Altan, Dijle Ayar
}

\begin{abstract}
Background: This study was conducted with the aim of determining how students' perceived smoking-cancer relationship and cardiovascular health attitudes affect childrens' views of smoking. Materials and Methods: The sample of this descriptive-cross sectional study comprised 574 subjects between the ages of 11-15. The data were collected using the Children's Cardiovascular Health Promotion Attitude Scale and the Children's Decisional Balance Measure for Assessing and Predicting Smoking Status. Correlation and logistic regression were used for analysis. Results: It was determined that a statistically significant relationship exists between the attitudes of children towards smoking and their ideas about the relationship of smoking with cancer, which is negative and low $(\mathbf{r}=-\mathbf{0 . 2 2 3})$. There was also a statistically significant relationship between their attitudes towards cardiovascular health and their attitudes towards smoking, again at a low level $(r=0.257)$. It was determined that children with ideas about smoking and cancer were 9.4 times less likely to have positive/negative attitudes towards smoking, while positive attitudes towards cardiovascular health made negative attitudes towards smoking 3.9 times less likely. Conclusions: It was determined that the attitudes of students towards cardiovascular health and their perceptions of smoking and cancer reduced the positive perceptions towards smoking.
\end{abstract}

Keywords: Smoking - perceived smoking-cancer relationship - hearth health and smoking

Asian Pac J Cancer Prev, 16 (7), 2801-2805

\section{Introduction}

According to World Health Organization (WHO) statistics for 2014, one person dies from smoking and the diseases caused by smoking every six seconds. Among these diseases, the two most important are cardiovascular diseases and cancer (WHO, Mortality and Global Health Estimates; 2014).

According to WHO data, approximately 17.3 million people died of various cardiovascular diseases across the globe in 2008 , and it is estimated that these figures will reach 23.3 million in 2030 unless certain measures are adopted. Approximately eight million people died of cancer in 2012, and again, unless certain measures are taken, it is estimated that the number of people who die of cancer will be approximately 14 million by 2022 . The majority of these deaths occur in less developed or developing countries (GSROND, 2011; Mortality and Global Health Estimates; 2014). As a developing country, the leading cause of death in Turkey in 2014 was cardiovascular diseases with $39.8 \%$, whereas cancer is rapidly approaching that percentage (Turkish Statistical Institute, 2014). These statistics reveal the importance of the reducing smoking to prevent cancer and cardiovascular diseases (GSROND, 2011; Turkish Statistical Institute, 2014; WHO 2014).

However, studies demonstrate that smoking rates are increasing both in Turkey and across the globe. Parallel to this increase, death rates resulting from cancer and heart diseases are also increasing (Bilir et al., 2007; Europe Region Tobacco Control report, 2007; Akdur, 2009; Turkish Statistical Institute, 2014; WHO 2014). Therefore, in order to reduce these death rates, the factors that affect smoking have to be known well, and measures have to be taken against them. Two such factors are ideas about the relationship between cancer and smoking and the attitudes towards cardiovascular health. Studies also reveal that the children with positive ideas about smoking are more likely to smoke, whereas the children who believe that smoking causes cancer and heart diseases have lower smoking rates (Chen et al., 2008; Ulgen et al., 2012; Karimy et al., 2013; Bektas et al., 2014; Parlak Sert et al., 2014).

When the literature is examined, it can be seen that the majority of the studies on the relationship between cancer and smoking and the attitudes towards heart diseases are conducted with individuals who have started smoking. 
Studies of children, on the other hand, tend to focus on the general health protection behaviors (Fritz, 2003, Kim, 2004; Hayman et al., 2004; Engels et al., 2005; Chen et al., 2008; Ulgen et al., 2012; Jeganathan et al., 2013; Karimy et al., 2013; Lotrean et al., 2013; Philip and Parambil, 2013; Bektas et al., 2014; Go et al., 2014; Kelder et al., 2014; Parlak Sert et al., 2014). No studies have been conducted in Turkey or abroad which show the nature of the relationship between two other important factors that affects smoking, ideas about the relationship between smoking and cancer with smoking and attitudes towards cardiovascular health.

Therefore, this study aims to determine how the perceived smoking-cancer relationship and Cardiovascular Health Attitudes on childrens' views of Smoking.

\section{Materials and Methods}

Aim

This is a descriptive-cross sectional study in order to evaluate the impact of the Studnets' perceived smokingcancer relationship and Cardiovascular Health Attitudes on childrens' views of Smoking.

\section{Population and sample}

The data were collected from two secondary schools selected from the Izmir Provincial Directorate of National Education using simple random sampling. In order to determine the sample size, the smoking rates of the children included in the studies conducted by Bektas et al. (2014), the average smoking pros/cons scores were taken as a basis, and the required sample for Type I error 0.05 and Type II error 0.20 (80\% Power) was calculated to be 98 students using the NCSS-PASS program. However, in order to clearly demonstrate the relationship between the variables in the study, 574 students who were willing to participate and had their parents' permission were included in the study. The data were collected by the researchers in both schools during a different period for each class (each period lasts 40 minutes), and during the classes of the teachers who allowed their class time to be used.

\section{Sampling criteria}

(i) Children and adolescents willing to participate in the study with consent forms from their parents; (ii) Children and adolescents who take part in the research study should be able to read and understand the questions included in the survey.

\section{Data collection tools}

The data for the study was collected using the Demographic Data Collection Form, the Children's Cardiovascular Health Promotion Attitude Scale and the Children's Decisional Balance Measure for Assessing and Predicting Smoking Status to assess the children's ideas and attitudes about smoking.

\section{The demographic data collection form}

The Demographic Data Collection Form contains questions related to the socio-demographic features of the children/adolescents participating in the study such as age, gender, class, parents' educational background, whether they have tried smoking, whether the parents smoke, the relationship between smoking and cancer and family income.

\section{The children's cardiovascular health promotion attitude scale}

The Children's Cardiovascular Health Promotion Attitude Scale (CCHPAS) is a Likert type scale developed by Arvidson (1990). Its validity and reliability in Turkish was established by Ozturk. The scale measures the cardiovascular health development attitudes of school children related to stress control, smoking, diet and exercise. The original scale study was conducted with 234 children that attend fourth, fifth and sixth grades. Its internal consistency reliability coefficient was found to be 0.80 , whereas the internal consistency reliability coefficients of its sub-dimensions were found to vary between 0.76 and 0.63 . The scale is a 4-point likert type scale that includes 16 items. The lowest possible score on the scale is 16 , and the highest is 64 . Only the twelfth item on the scale has a reverse direction. Since it is easier for primary school children to answer multiple choice questions, a, b, c, and d options were chosen for the scale items. In order to determine the attitudes of students towards cardiovascular health, the median was used. Scores below the median were assessed as a negative attitude towards cardiovascular health, whereas the median and scores above it were considered positive attitudes towards cardiovascular health.

\section{The decisional balance scale (DBS)}

The original DBS was developed by Velicer et al. (1985) in order to assess the perception of adults towards the harms and benefits of smoking. It includes 24 items. The Children's DBS was derived from the adult DBS by Pallonen et al. (1998) in 1998 and it was reduced to 12 items. The Children's DBS includes six (6) items of benefit and six (6) items of harm sub-criteria that correspond to 12 circumstances pointing to the harms and benefits of smoking. It is a likert type scale scored between 1 and 5 . The scores for the children's DBS sub-dimensions vary between 6 and 30. If the benefit subscale's score average is high, this indicates strong ideas about the benefits of smoking. If the harm subscale's score average is high, this indicates strong ideas about the harms of smoking (Bektas et al., 2010b) For Turkish children, the reliability and validity of the scale was established by Bektas, Ozturk and Armstrong (2010). The sample of their study included of 642 students in grades 4 through 8 . For the benefit sub-dimension of the scale, the Cronbach alpha reliability coefficient was found to be 0.74 , whereas this coefficient was found to be 0.78 for the harm sub-dimension. The scale's testing-retesting reliability coefficients were found to be $\mathrm{r}=0.848$ for the benefit sub-dimension and $\mathrm{r}=0.698$ for the harm sub-dimension. The total variance revealed for each factor was found to be $22 \%$ for the benefit sub-dimension and $28 \%$ for the harm sub-dimension. As a result of affirmative factor analysis, the correlation coefficient between the benefit and harm sub-dimensions of DBS was found to be $r=0.49$. Thus, it was determined 
that DBS is a reliable and valid tool that may be used for Turkish culture (Bektas et al., 2010b).

\section{Dependent and independent variables}

The dependent variable of the research is the students' attitudes towards smoking, whereas the independent variables are their perception about the relationship between cancer and smoking and their attitudes towards cardiovascular health.

\section{Data analysis}

The demographic properties of the students were assessed using percentages and averages. Their attitudes towards cardiovascular health, perception about the relationship between smoking-cancer and attitudes towards smoking were evaluated using correlation, whereas their perception about the relationship of cancer-smoking and the effect of their attitudes towards cardiovascular health on their attitudes towards smoking were evaluated using logistic regression. The significance level was 0.05 .

\section{Ethical issues}

Prior to the research, the permissions of the owners of the scales used in the study were obtained. The written consent of Dokuz Eylul University's Non-Invasive Research Ethics Board was obtained in a decision dated 06/11/2014 and numbered 2014/34-04. Written institutional permission was obtained from the Provincial Directorate of National Education, and finally, written consent by the children and parents was obtained.

\section{Results}

The average age of the children who participated in the study is $11.8+1.3$. Of the children, $34.7 \%$ are in fifth grade, $31.9 \%$ are in sixth grade, $21 \%$ are in seventh grade and $12 \%$ are in eighth grade. Of the mothers, $36.3 \%$ are high-school graduates, and $35.2 \%$ of the fathers. are highschool graduates. Of the mothers, $30.1 \%$ smoke, $47.5 \%$ of the fathers and $5.3 \%$ of the siblings smoke. Of the children, $3 \%$ had tried smoking. It was determined that $94.1 \%$ of the children have negative attitudes towards smoking and 98\% have positive attitudes towards cardiovascular health.

Table 1. Correlation among Students' Perceived Smoking-cancer Relationship, Cardiovascular Health Attitudes and Childrens' Views of Smoking

\begin{tabular}{lcc}
\hline & \multicolumn{2}{c}{ Attitude about Smoking } \\
& $\mathrm{r}$ & $\mathrm{p}$ \\
\hline Smoking cancer relationship & $-0.223 *$ & 0.000 \\
Heart Health Attitude & $0.257 * *$ & 0.000 \\
\hline *Spearmen Correlation **Pearson Correlation &
\end{tabular}

It was determined that a statistically significant relationship exists between the attitudes of children towards smoking and their ideas about the relationship between smoking and cancer, which is negative and low $(r=-0.223)$. There is also a statistically significant relationship between their attitudes towards cardiovascular health and their attitudes towards smoking, again at a low level ( $\mathrm{r}=0.257)$ (Table 1).

The logistic regression results of the children's perception of the relationship between smoking and cancer and their attitudes towards cardiovascular health are presented in Table 2. It was determined that children with ideas about smoking and cancer were 9.4 times less likely to have positive attitudes towards smoking (OR: 9.347, $95 \%$, CI: 3.126-28.448), while positive attitudes towards cardiovascular health made positive attitudes towards smoking 3.9 times less likely (OR: 4.702, $95 \%$, CI: 1.024-21.583) (Table 2).

\section{Discussion}

This study determined that a statistically significant relationship exists between the attitudes of children towards smoking and their perception about the relationship between smoking-cancer, which is negative and low $(\mathrm{r}=-0.223)$ and between their attitudes towards cardiovascular health and their attitudes towards smoking, again at a lower level $(r=0.257)$ (Table 1). Studies demonstrate that children who believe that smoking causes cancer or who have lost a relative due to cancer that is caused by smoking have even more negative attitudes towards smoking (Kelder et al., 1994; Fritz, 2003; Hayman et al., 2004; Kim, 2004; Engels et al., 2005; Jeganathan et al., 2013; Karimy et al., 2013; Lotrean, Loghin et al., 2013; Philip and Parambil, 2013; Hock et al., 2014). Moreover, they show that the children who develop positive attitudes towards cardiovascular health and receive training in this field are less likely to try smoking or to smoke since they develop negative attitudes towards smoking (Kelder et al., 1994; Fritz, 2003; Hayman et al., 2004; Kim, 2004; Engels et al., 2005; Jeganathan et al., 2013; Karimy et al., 2013; Lotrean, Loghin et al., 2013; Philip and Parambil, 2013; Hock et al., 2014). The findings of this study correspond to the findings in the literature.

This study determined that children with perception about smoking-cancer relationship were 9.4 times less likely to have positive attitudes towards smoking (OR: 9.347, $95 \%$, CI: 3.126-28.448), while positive attitudes towards cardiovascular health made positive attitudes towards smoking 3.9 times less likely (OR: 4.702, 95 $\%$, CI: 1.024-21.583) (Table 2). The literature indicates that smoking rates rise with positive attitudes towards smoking, while several factors affect these positive

Table 2. Prediction of Perceived Smoking-Cancer Relationship and Cardiovascular Health Attitudes on Childrens' Views of Smoking

\begin{tabular}{|c|c|c|c|c|c|c|c|c|}
\hline & \multirow[t]{2}{*}{$\mathrm{B}$} & \multirow[t]{2}{*}{ S.E. } & \multirow[t]{2}{*}{ Wald } & \multirow[t]{2}{*}{ df } & \multirow[t]{2}{*}{ Sig. } & \multirow[t]{2}{*}{$\operatorname{Exp}(B)$} & \multicolumn{2}{|c|}{$95 \% \mathrm{CI}$} \\
\hline & & & & & & & Lower & Upper \\
\hline Constant & $-1,150$ & 0.426 & 7,280 & 1 & 0.007 & 0.316 & & \\
\hline Smoking cancer relationship & 2,245 & 0.564 & 15,855 & 1 & 0.000 & 9,437 & 3,126 & 28,488 \\
\hline Heart Health Attitude & 1,548 & 0.778 & 3,964 & 1 & 0.046 & 4,702 & 1,024 & 21,583 \\
\hline
\end{tabular}


attitudes. One such important factor is having a cancer patient in the family or having lost a family member to cancer (Kelder et al., 1994; Fritz, 2003; Hayman et al., 2004; Kim, 2004; Engels et al., 2005; Jeganathan et al., 2013; Karimy et al., 2013; Lotrean, Loghin et al., 2013; Philip and Parambil, 2013; Hock et al., 2014). The most significant reason for this is that children recognize the problems that their relatives encounter during the diagnosis and treatment stage, and identify with these situations. Since they would like to prevent these problems in their own lives, they exhibit negative attitudes towards smoking, therefore in comparison to the children who believe that there is no relationship between cancer and smoking, it can be argued that they develop ten times more negative attitudes towards smoking. On the other hand, highlighting smoking's negative impact on cardiovascular health as part of the information provided both during classes and in daily life, helps children understand the relationship between heart disease and smoking, and gives them the idea that they might get heart disease if they smoke. Therefore, as positive attitudes towards cardiovascular health increase, negative attitudes towards smoking may also proliferate (Kelder et al., 1994; Bandura, 1998; Fritz, 2003; Hayman et al., 2004; Kim, 2004; Engels et al., 2005; Bektas et al., 2010b; Jeganathan et al., 2013; Karimy et al., 2013; Lotrean et al., 2013; Philip and Parambil, 2013; Bektas et al., 2014; Hock et al., 2014). Moreover, television advertisements and public service announcements highlighting the relationship between cancer and smoking or incorporating elements that encourage smoking within advertisements/television programs can positively and negatively influence attitudes towards smoking (Cavazos-Rehg et al., 2013; Chang et al., 2014). It is believed that the laws adopted in Turkey after 2008 targeting smoking, the Mpower program's growing popularity in Turkey, highlighting the relationship between smoking and cancer in public service announcements also influenced the students' negative attitudes towards smoking (National Tobacco Control Program and Action Plan, 2008).

In conclusion, this study determined that children who have a positive attitude towards cardiovascular health are four times more likely to have a negative attitude towards smoking, children who think that there is a relationship between smoking and cancer are nine times more likely to have a negative attitude towards smoking. Thus, educational initiatives for children that focus on the relationship between cancer-smoking and the development of cardiovascular health should be implemented in smoking prevention programs.

\section{References}

Akdur R (2009). Smoking epidemic in youth, smoking and health symposium, April, Ankara. Access date:10.01.2015 http://www.ssuk.org.tr/

Bandura A (1998). Health promotion from the perspective of social cognitive theory. Psychology Hlth, 13, 623-49.

Bektas M, Ozturk C, Armstrong M (2010a). An approach to children's smoking behaviors using social cognitive learning theory. Asian Pac J Cancer Prev, 11, 1143-9.
Bektas M, Ozturk C, Armstrong M (2010b). Psychometric properties of a translated decisional balance scale for assessing and predicting children's smoking status. Anadolu Psikiyatri Derg, 11, 327-34.

Bektas M, Ozturk C, Karatas H, Bektas I (2014). Effects of student perceptions of social skills on their perception of smoking. Asian Pac J Cancer Prev, 15, 5937-40.

Bilir N (2007). European tobacco control report. WHO Turkiye Ofisi, Ankara

Cavazos-Rehg AP, Krauss JM, Spitznagel EL, Grucza AR, Bierut LJ (2013). The hazards of new media: youth's exposure to tobacco ads/promotions. Nicotine Tob Res, 16, 437-44.

Chang F, Miao N, Lee C, et al (2014). The association of media exposureand media literacy with adolescent alcohol and tobacco use. J Health Psychol [Epub ahead of print].

Chen HS, Horner SD, Percy MS, et al (2008). Stages of smoking acquisition of young taiwanese adolescents: Self-efficacy and decisional balance. Res Nurs Health, 31, 119-29.

Edwards L (2002). Research priorities in school nursing: Adelphi process. J Sch Nurs, 18, 157-62.

Engels RCME, Noom MJ, Hale WW, Vries H de (2005). Selfefficacy and emotional adjustment as precursors of smoking in early adolescence. Subst Use Misuse, 40, 1883-93.

Go AS, Mozaffarian D, Roger VL, et al (2014). Heart disease and stroke statistics-2014 update: a report from the American heart association. Circulation, 129, 399-410.

GSROND (2011). Global status report on noncommunicable diseases 2010. Geneva, World Health Organization.

Hayman LL, Williams CL, Daniels SR, et al (2004). Cardiovascular health promotion in the schools: a statement for health and education professionals and child health advocates from the committee on atherosclerosis, hypertension, and obesity in youth (AHOY) of the council on cardiovascular disease in the young, American heart association. Circulation, 110, 2266-75.

Hock LK, Ghazali SM, Cheong KC, et al (2014). Prevalence and factors associated with smoking intentions among nonsmoking and smoking adolescents in kota tinggi, Johor, Malaysia. Asian Pac J Cancer Prev, 15, 4359-66.

Jeganathan PD, Hairi NN, Al Sadat N, Chinna K. (2013). Smoking stage relations to peer, school and parental factors among secondary school students in Kinta, Perak. Asian Pacific J Cancer Prev, 14, 3483-9.

Karimy M, Niknami S, Heidarnia AR, et al (2013). Refusal self efficacy, self esteem, smoking refusal skills and water pipe (Hookah) smoking among Iranian male adolescents. Asian Pac J Cancer Prev, 14, 7283-88.

Kelder SH, Peny CL, Klepp K, Lytle LL (1994). Longitudinal tracking of adolescent smoking, physical activity, and food choice behaviors. Am J Public Health, 84, 1121-26.

Lotrean LM, Loghin CR, Popa M, De Vries H (2013). Smoking prevention for adolescents in Romanian schools. Asian Pacific J Cancer Prev, 14, 7017-21.

Ozturk C, Bektas M, Mert O (2014). Effects of cigarette smoking across three generations and of perceptions of the smokingcancer relationship on the cigarette smoking status of Turkish university students. Asian Pac J Cancer Prev, 15, 4527-33.

Ozturk H, Bahar Z (2014) Childrens' cardiovascular health promotion attitude scale's validity and Reliability. DEUHYO $E D, 7,92-7$.

Parlak Sert H, Bektas M, Ozturk C (2014). Effects of self-concept levels and perceived academic achievements of Turkish students on smoking perceptions. Asian Pac J Cancer Prev, 15, 1307-12.

Philip PM, Parambil NA, Bhaskarapillia, Balasubramanian S (2013). Evaluation of a specially designed tobacco control program to reduce tobacco use among school children in 
Kerala. Asian Pac J Cancer Prev, 14, 3455-9.

Turkish Statistical Institute (2014). Cause of death statistics 2013. Access Date: 01.10.2014 http://www.tuik.gov.tr/ PreHaberBultenleri.do?id=16198.

Ulgen H, Ozturk C, Armstrong M (2012). Effect of self-efficacy on Turkish children's perceptions of the advantages/ disadvantages of smoking. Asian Pac J Cancer Prev, 13, 795-8.

National Tobacco Control Programme and Action Plan (2008). The hazards of new media: youth's exposure to tobacco Ads/ Promotions. Access Date: 01.10.2014 http://sbu.saglik.gov. tr/Ekutuphane/kitaplar/t15.pdf

WHO Report on the Global Tobacco Epidemic (2014). Access Date: 01.10.2014. http://www.who.int/tobacco/global_ report/en/

WHO; Mortality and global health estimates, Access Date: 01.10.2014. http://www.who.int/gho/mortality_burden_ disease/en/ 